\title{
Phase I clinical trial of the base excision repair inhibitor methoxyamine in combination with fludarabine for patients with advanced hematologic malignancies
}

\author{
Paolo F. Caimi ${ }^{1,2}$, Brenda W. Cooper ${ }^{1,2}$, Basem M. William ${ }^{3}$, Afshin Dowlati ${ }^{1,2}$, Paul \\ M. Barr ${ }^{4}$, Pingfu Fú ${ }^{5}$, John Pink ${ }^{1}$, Yan $X_{u^{1}}$, Hillard M. Lazarus ${ }^{1,2}$, Marcos de Lima ${ }^{1,2}$ \\ and Stanton L. Gerson ${ }^{1,2}$ \\ ${ }^{1}$ Case Comprehensive Cancer Center, Cleveland, Ohio, USA \\ ${ }^{2}$ Division of Hematology and Oncology, Department of Medicine, University Hospitals Seidman Cancer Center, Cleveland, \\ Ohio, USA \\ ${ }^{3}$ Division of Hematology. The Ohio State University Medical School, Columbus, Ohio, USA \\ ${ }^{4}$ Division of Hematology and Oncology, Department of Medicine, University of Rochester, Rochester, New York, USA \\ ${ }^{5}$ Department of Biostatistics, Case Western Reserve University, Cleveland, Ohio, USA
}

Correspondence to: Paolo F. Caimi, email: paolo.caimi@case.edu

Keywords: phase I, methoxyamine, base excision repair, hematologic malignancies, pharmacokinetics

Received: April 14, $2017 \quad$ Accepted: July 26, $2017 \quad$ Published: August 09, 2017

Copyright: Caimi et al. This is an open-access article distributed under the terms of the Creative Commons Attribution License 3.0 (CC BY 3.0), which permits unrestricted use, distribution, and reproduction in any medium, provided the original author and source are credited.

\section{ABSTRACT}

Purpose: We determined the safety, pharmacokinetics, pharmacodynamics and recommended phase II dose of the base excision repair blocker methoxyamine combined with fludarabine.

Materials and Methods: This was a phase I study with intravenous fludarabine (25 mg/m², days $1-5)$, and methoxyamine $\left(15 \mathrm{mg} / \mathrm{m}^{2}-120 \mathrm{mg} / \mathrm{m}^{2}\right.$, once). A maximum of six cycles were given. Adult patients with relapsed/refractory hematologic malignancies, excluding acute myeloid leukemia, were eligible.

Results: Twenty patients were treated; diagnoses included CLL/SLL $(n=10)$, follicular lymphoma $(n=3)$, DLBCL $(n=3)$, mantle cell lymphoma $(n=1)$, anaplastic large cell lymphoma $(n=1)$ and plasma cell myeloma $(n=2)$. No DLTs were observed and dose escalation reached the maximum planned dose. Hematologic toxicity was frequent; most common grade 3-4 toxicities were lymphopenia (70\%), neutropenia $(60 \%)$, leukopenia $(50 \%)$ and anemia $(40 \%)$. Four patients achieved a partial remission and 8 achieved stable disease. The drug combination resulted in increased DNA damage measured with the Comet assay.

Conclusions: Methoxyamine combined with fludarabine was safe and well tolerated. Hematologic toxicity was comparable to single agent fludarabine. Activity appears to correlate with increased levels of DNA damage. Further studies will examine use of this combination of as part conditioning regimens of stem cell transplant and use of methoxyamine as fludarabine dose-sparing agent.

\section{INTRODUCTION}

The purine analog fludarabine is most commonly used in the treatment of chronic lymphocytic leukemia (CLL) $[1,2]$ but is also part of the therapeutic armamentarium for indolent lymphomas $[3,4]$ and myeloid malignancies [5]. In CLL, fludarabine alone achieves superior response rates and progression free survival (PFS) than alkylating agents, albeit without overall survival improvement (OS) [1, 6]. Fludarabine is also an important component of reduced intensity conditioning regimens for allogeneic stem cell transplant [7].

The active metabolite fludarabine triphosphate (F-ara-ATP) exerts its cytotoxic activity through 
incorporation into DNA. In replicating cells, F-ara-ATP forms abnormal base pairs with thymine (F:T), interferes with DNA chain elongation by DNA polymerase $\alpha$ [8] and inhibits several other enzymes involved in DNA synthesis $[9,10]$. In resting cells, F-ara-ATP is incorporated into DNA by the nucleotide excision repair pathway (NER) and terminates the DNA polymerization stage of the NER process $[11,12]$. The resulting DNA damage leads to cell death, mediated either by p53 [13, 14] or PARP [10].

The base excision repair pathway (BER) is a DNA repair mechanism distinct from NER, capable of recognizing single base pair abnormalities [15], including those caused by exposure to environmental mutagens and antineoplastic agents [16-19]. The initial step in BER is removal of the abnormal base by a specific DNA glycosylase, forming an apurinic/apyrimidinic (AP) site. The AP site is cleaved by AP endonuclease (APE), generating a single - strand DNA break, followed by incorporation of the correct base and subsequent annealing by DNA polymerase $\beta$ and DNA ligase, respectively [20]. The activity of the BER system confers resistance against antineoplastic agents that cause DNA damage [21]. More importantly, BER inhibition augments the cytotoxic activity of DNA damaging agents [21-23].

Methoxyamine is a small organic amine that inhibits BER by reacting in a specific fashion with the aldehyde group in the sugar moiety present at the AP site. Methoxyamine-bound AP sites are refractory to the lyase activity of APE, block further actions of BER pathway and result in persistent DNA lesions and arrested DNA replication, causing additional DNA damage by acting as topoisomerase II $\alpha$ poisons [24]. Methoxyamine enhances the in vitro and in vivo activity of alkylating agents in colon, ovarian and breast cancer cell lines and xenograft models [25-29]. In a previous report, the addition of methoxyamine to fludarabine resulted in increased markers of DNA double strand breaks in cell lines and primary CLL cells, including increased Comet tail length and increased $\gamma \mathrm{H} 2 \mathrm{AX}$ expression, and result in induction of topoisomerase II expression [24]. In contrast, methoxyamine alone does not result in DNA double strand breaks or increased apoptosis compared to untreated controls [24, 30]. In mouse xenograft studies, methoxyamine augmented the antitumor activity of fludarabine, while methoxyamine alone did not have an antineoplastic effect [24].

Based on this preclinical data, we conducted a phase I study investigating the safety and tolerability of the combination of methoxyamine and fludarabine in the treatment of advanced hematologic malignancies.

\section{RESULTS}

\section{Patient characteristics}

Twenty patients were enrolled and treated in this clinical trial. Median age was 64 years (range 45 to 82);
$60 \%$ of patients were men. The diagnoses included CLL /small lymphocytic lymphoma (SLL) $(n=10)$ follicular lymphoma $(n=3)$, diffuse large $\mathrm{B}$ cell lymphoma (DLBCL) $(n=3)$, mantle cell lymphoma $(n=1)$ and plasma cell myeloma $(n=2)$. The median number of prior lines of therapy was 3 (range $1-5$ ) and 8 out of $10 \mathrm{CLL} /$ SLL patients had received fludarabine, with 2 patients considered fludarabine refractory, relapsing within 6 months after a fludarabine - containing regimen (Table 1). All patients who completed at least one cycle of fludarabine and methoxyamine were considered evaluable for safety.

\section{Treatment}

In cycle 1, patients received fludarabine at a dose of $25 \mathrm{mg} / \mathrm{m}^{2}$, intravenously over 1 hour on days $1-5$ of each cycle. Methoxyamine was infused on day 2 at the assigned dose level as intravenous infusion over 30 minutes, before fludarabine infusion. In cycle 2 and subsequent cycles, methoxyamine was given on day 1 of each cycle, before the infusion of fludarabine. The median number of cycles administered was 3 (range, 1 to 6). Seventeen patients discontinued treatment before completing the planned 6 cycles of therapy. The reasons for discontinuing therapy included disease progression $(n=7,35 \%)$, adverse events (AEs) $(n=4,25 \%$ : grade 2 fatigue $[n=2]$; grade 3 pulmonary infection $[n=1]$ and prolonged neutropenia $[n=1])$; patient choice $(n=4,20 \%)$, continuation to allogeneic stem cell transplant $(n=2,10 \%)$. Three patients completed the full plan of six cycles of treatment.

\section{Pharmacokinetics}

The results of pharmacokinetic analyses are presented in Table 2. The half-life of methoxyamine ranged from 27.8 to 68.5 hours; median half-life was 40.1 hours; there was no statistically significant difference in the average half-life between dose levels. Linear regression analysis demonstrated a statistically significant correlation between methoxyamine dose and area under the curve (AUC) of plasma concentration $\left(p<0.0001 ; \mathrm{R}^{2}=0.67\right)$, as well as maximum plasma concentration $\left(\mathrm{C}_{\max }\right)\left(p<0.0001 ; \mathrm{R}^{2}\right.$ $=0.73)$. Figure 1 illustrates the effect of methoxyamine dose on its plasma concentration over time, suggesting exponential decrease over time, compatible with first order elimination kinetics. Modeling with linear regression analysis of the natural logarithm of methoxyamine concentration $(\operatorname{Ln}[\mathrm{MX}])$ and time showed statistically significant correlation at each dose level $\left(\mathrm{R}^{2}=0.901,0.744\right.$, $0.748,0.801$ and 0.785 for $15,30,60,90$ and $120 \mathrm{mg} / \mathrm{m}^{2}$ dose levels, respectively; $p<0.0001$ for all correlations), confirming first order kinetics for methoxyamine.

\section{Pharmacodynamic studies - comet assay}

Comet tail length presented a statistically significant increase from baseline measured at 24, 27, 48, 72 and 
Table 1: Patient demographic and clinical characteristics

\begin{tabular}{|c|c|}
\hline Characteristic & No. of patients \\
\hline Patients who received at least one cycle of fludarabine and methoxyamine & 20 \\
\hline $\begin{array}{l}\text { Age, years } \\
\text { Median } \\
\text { Range }\end{array}$ & $\begin{array}{l}64 \\
45-82\end{array}$ \\
\hline $\begin{array}{l}\text { Sex } \\
\text { Male } \\
\text { Female }\end{array}$ & $\begin{array}{l}12(60 \%) \\
8(40 \%)\end{array}$ \\
\hline $\begin{array}{l}\text { Number of prior treatments } \\
1-2 \\
\geq 3\end{array}$ & $\begin{array}{l}7(35 \%) \\
13(65 \%)\end{array}$ \\
\hline Prior treatment with fludarabine & $8(40 \%)$ \\
\hline $\begin{array}{l}\text { Diagnoses } \\
\text { CLL/SLL } \\
\text { Follicular lymphoma } \\
\text { Diffuse large B cell lymphoma } \\
\text { Mantle cell lymphoma } \\
\text { Plasma cell myeloma }\end{array}$ & $\begin{array}{l}10(50 \%) \\
3(15 \%) \\
3(15 \%) \\
1(5 \%) \\
2(10 \%)\end{array}$ \\
\hline $\begin{array}{l}\text { Eastern Cooperative Oncology Status } \\
0 \\
1 \\
2\end{array}$ & $\begin{array}{l}4(20 \%) \\
15(75 \%) \\
1(5 \%)\end{array}$ \\
\hline
\end{tabular}

Table 2: Pharmacokinetic parameters of methoxyamine

\begin{tabular}{lcccc}
\hline Dose & $\begin{array}{c}\text { Half Life, mean } \\
( \pm \text { SEM) }\end{array}$ & $\begin{array}{c}\text { Cmax, mean } \\
( \pm \text { SEM) }\end{array}$ & $\begin{array}{c}\text { AUC, mean } \\
( \pm \text { SEM) }\end{array}$ & $\begin{array}{c}\text { Clearance, mean } \\
( \pm \text { SEM) }\end{array}$ \\
\hline $\left.\mathbf{m g} / \mathbf{m}^{\mathbf{2}}\right)$ & $(\mathbf{h})$ & $\mathbf{( n g / m L )}$ & $(\mathbf{h} \mathbf{n g} / \mathbf{m L})$ & $\left(\mathbf{m L} / \mathbf{h} / \mathbf{m}^{2}\right)$ \\
\hline 15 & $40.9( \pm 7.0)$ & $12.6( \pm 1.3)$ & $691.6( \pm 44.8)$ & $22062.0( \pm 1445.4)$ \\
30 & $41.6( \pm 8.9)$ & $18.8( \pm 5.4)$ & $1044.4( \pm 301.3)$ & $34241.2( \pm 9978.7)$ \\
60 & $44.9( \pm 3.1)$ & $37.5( \pm 8.3)$ & $2502.4( \pm 816.3)$ & $29014.3( \pm 7954.4)$ \\
90 & $46.0( \pm 5.9)$ & $100.0( \pm 21.3)$ & $6560.6( \pm 1560.1)$ & $16035.0( \pm 4895.5)$ \\
120 & $45.0( \pm 5.2)$ & $100.4( \pm 13.8)$ & $6358.2( \pm 1042.2)$ & $22180.8( \pm 4371.2)$ \\
\hline
\end{tabular}

AUC: area under the curve of plasma concentration; Cmax: maximum plasma concentration.

96 hours after treatment was started $(p<0.0001)$. There was no difference between comet tail length measured at baseline and 2 hours after first dose of fludarabine. There was no statistically significant difference in comet tail length between methoxyamine dose levels.

Linear regression analysis showed the change in WBC number after 1 week of treatment presented a statistically significant correlation with comet tail length at baseline $(p=0.029), 2(p=0.038), 24(p=0.030)$ and $27(p=0.032)$ hours after treatment. Correlation with later time points (48, 72 and 96 hours) was not statistically significant.
In patients with CLL and circulating malignant lymphocytes $(n=7)$, the average comet tail length increased 2.25 times over the first week of therapy (95\% CI 0.81-3.68). The median absolute lymphocyte count decreased from $19.2 \times 10^{9}$ lymphocytes/L (range $3.94-182.7$ ) at baseline to $2.2 \times 10^{9}$ lymphocytes/L (range 0.37-137.2) at day 7 (Figure 4 and Supplementary Table 1). Linear regression showed a statistically significant correlation between the percentage of decrease in circulating lymphocytes after 7 days and comet tail length at $24\left(\mathrm{R}^{2}=0.93, p=0.0004\right), 48\left(\mathrm{R}^{2}=0.84, p=0.004\right), 72$ $\left(\mathrm{R}^{2}=0.86, p=0.003\right)$, and $96\left(\mathrm{R}^{2}=0.72, p=0.02\right)$ hours. 


\section{Safety}

Hematologic toxicity was common, including anemia $(n=20,100 \%)$, lymphopenia $(n=16,80 \%)$, neutropenia $(n=15,75 \%)$ and thrombocytopenia $(n=13,65 \%)$. The most common non-hematologic toxicities included fatigue $(n=17,85 \%)$, nausea $(n=13,65 \%)$, hypocalcemia $(n=11,55 \%)$, anorexia $(n=10,50 \%)$ and paresthesias $(n=10,50 \%)$. Regarding grade $\geq 3$ AEs, the most common ( $\geq 10 \%$ of patients) grade 3 or 4 AEs observed were hematologic, including lymphopenia $(n=14$, $70 \%)$, neutropenia $(n=12,60 \%)$, anemia $(n=8,40 \%)$ and thrombocytopenia $(n=5,25 \%)$. Comparison of the incidence of grade $\geq 3$ adverse events between patients who received up to three cycles of treatment vs. those that received more than three cycles showed there was only a statistically significant difference in the incidence of leukopenia $(p=0.03)$, with no difference observed in the incidence of other hematologic toxicities.

Infection was the only common grade 3-4 nonhematologic toxicity $(n=3,15 \%)$. Six patients presented a decrease in haptoglobin without clinical evidence of autoimmune hemolytic anemia or increases in plasma bilirubin and lactate dehydrogenase. All grade $\geq 3$ AEs and all AEs occurring in more than one patient are summarized in Table 3.

\section{Efficacy and survival}

Four patients $(20 \%)$ achieved partial response $(\mathrm{CLL} / \mathrm{SLL}=3$, follicular lymphoma $=1)$, and 8 patients $(40 \%)$ exhibited stable disease (CLL/SLL
$=6$, follicular lymphoma $=2$, DLBCL $=1)($ Figure 2). Six CLL/SLL subjects had lymphocyte counts over $5 \times 10^{9}$ lymphocytes $/ \mathrm{L}$ and 5 presented normalization of lymphocytosis, with a median decrease of $95 \%$ in the first 7 days of therapy (range $29-99 \%$, median baseline lymphocyte count $=72 \times 10^{9}$ lymphocytes $/ \mathrm{L}$; median lymphocyte count on day $8=1.75 \times 10^{9}$ lymphocytes $/ \mathrm{L}$ ).

Two subjects (CLL, follicular lymphoma) proceeded to reduced intensity allogeneic stem cell transplant and have not relapsed. One subject received maintenance rituximab for two years and has not progressed. All remaining subjects have either progressed $(n=6)$ or died $(n=11)$.

After a median follow up of 27 months, 2-year OS was 55\% (95\% CI 33-77\%) (Figure 3). For patients who achieved at least stable disease, 2 - year OS estimate is $92 \%(95 \%$ CI $76-100 \%)$ with a median time to next therapy of 9 months (95\% CI 2-28).

\section{DISCUSSION}

The BER system represents a potential mechanism of resistance to fludarabine. Methoxyamine is a first in class inhibitor of BER. The results of this phase I trial demonstrate that this drug can be safely administered in combination with fludarabine. There were no dose limiting toxicities and the maximum tolerated dose was not reached.

In vitro and animal studies suggest that the addition of methoxyamine to fludarabine increases the antitumor effect of the latter without added cytotoxicity to normal hematopoietic cells [24]. In accordance with

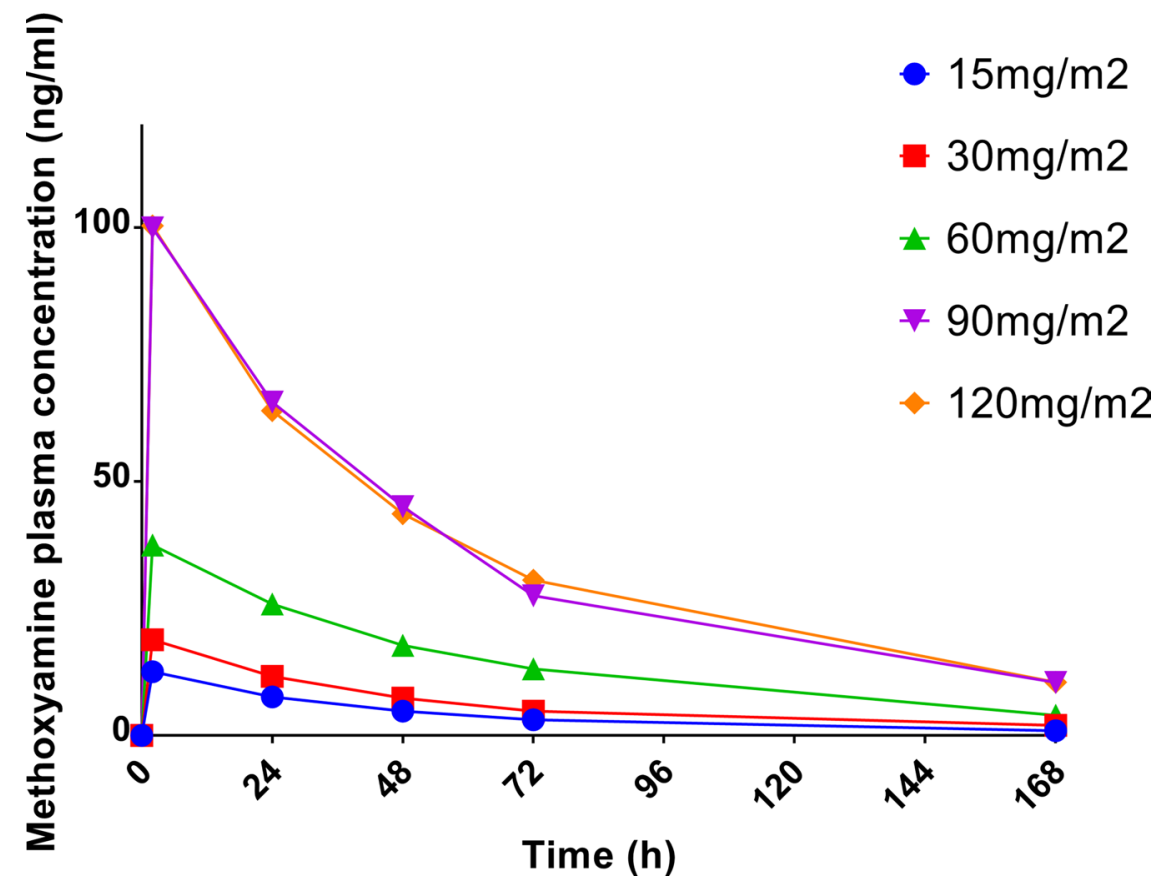

Figure 1: Average methoxyamine concentration in plasma over time after a single administration. 
Table 3: Adverse events in subjects treated with fludarabine and methoxyamine

\begin{tabular}{|c|c|c|c|c|}
\hline \multirow{2}{*}{$\begin{array}{l}\text { Toxicity } \\
\text { Hematologic }\end{array}$} & \multicolumn{2}{|c|}{ All Grades (\%) } & \multicolumn{2}{|c|}{ Grade 3-4 (\%) } \\
\hline & $N$ & $\%$ & $N$ & $\%$ \\
\hline Leukopenia & 17 & 85 & 10 & 50 \\
\hline Neutropenia & 15 & 75 & 12 & 60 \\
\hline Anemia & 20 & 100 & 8 & 40 \\
\hline Thrombocytopenia & 13 & 65 & 5 & 25 \\
\hline Lymphopenia & 16 & 80 & 14 & 70 \\
\hline \multicolumn{5}{|l|}{ Gastrointestinal } \\
\hline Anorexia & 10 & 50 & 0 & 0 \\
\hline Constipation & 9 & 45 & 0 & 0 \\
\hline Diarrhea & 5 & 25 & 1 & 5 \\
\hline Nausea & 13 & 65 & 0 & 0 \\
\hline Vomiting & 5 & 25 & 0 & 0 \\
\hline \multicolumn{5}{|l|}{ Neurologic } \\
\hline Insomnia & 7 & 35 & 1 & 5 \\
\hline Dizziness & 2 & 10 & 0 & 0 \\
\hline Paresthesias & 10 & 50 & 0 & 0 \\
\hline Pain & 8 & 40 & 1 & 5 \\
\hline \multicolumn{5}{|l|}{ Respiratory } \\
\hline Cough & 2 & 10 & 0 & 0 \\
\hline Dyspnea & 7 & 35 & 0 & 0 \\
\hline \multicolumn{5}{|l|}{ General } \\
\hline Fatigue & 17 & 85 & 0 & 0 \\
\hline \multicolumn{5}{|l|}{ Cutaneous/Dermatologic } \\
\hline Alopecia & 3 & 15 & 0 & 0 \\
\hline Erythema & 2 & 10 & 0 & 0 \\
\hline Pruritus & 2 & 10 & 0 & 0 \\
\hline \multicolumn{5}{|l|}{ Infectious } \\
\hline Fever & 6 & 30 & 1 & 5 \\
\hline Infection & 5 & 25 & 3 & 15 \\
\hline \multicolumn{5}{|l|}{ Cardiovascular } \\
\hline Edema & 3 & 15 & 0 & 0 \\
\hline \multicolumn{5}{|l|}{ Laboratory } \\
\hline Hyperbilirubinemia & 8 & 40 & 0 & 0 \\
\hline Hypokalemia & 3 & 15 & 0 & 0 \\
\hline Hyperuricemia without TLS & 3 & 15 & 1 & 5 \\
\hline Hypoalbuminemia & 7 & 35 & 1 & 5 \\
\hline Hyponatremia & 8 & 40 & 0 & 0 \\
\hline Hypocalcemia & 11 & 55 & 0 & 0 \\
\hline Transaminase elevation & 5 & 25 & 1 & 5 \\
\hline Creatinine elevation & 5 & 25 & 0 & 0 \\
\hline Haptoglobin decrease & 6 & 30 & 0 & 0 \\
\hline
\end{tabular}


Disease response to fludarabine and methoxyamine

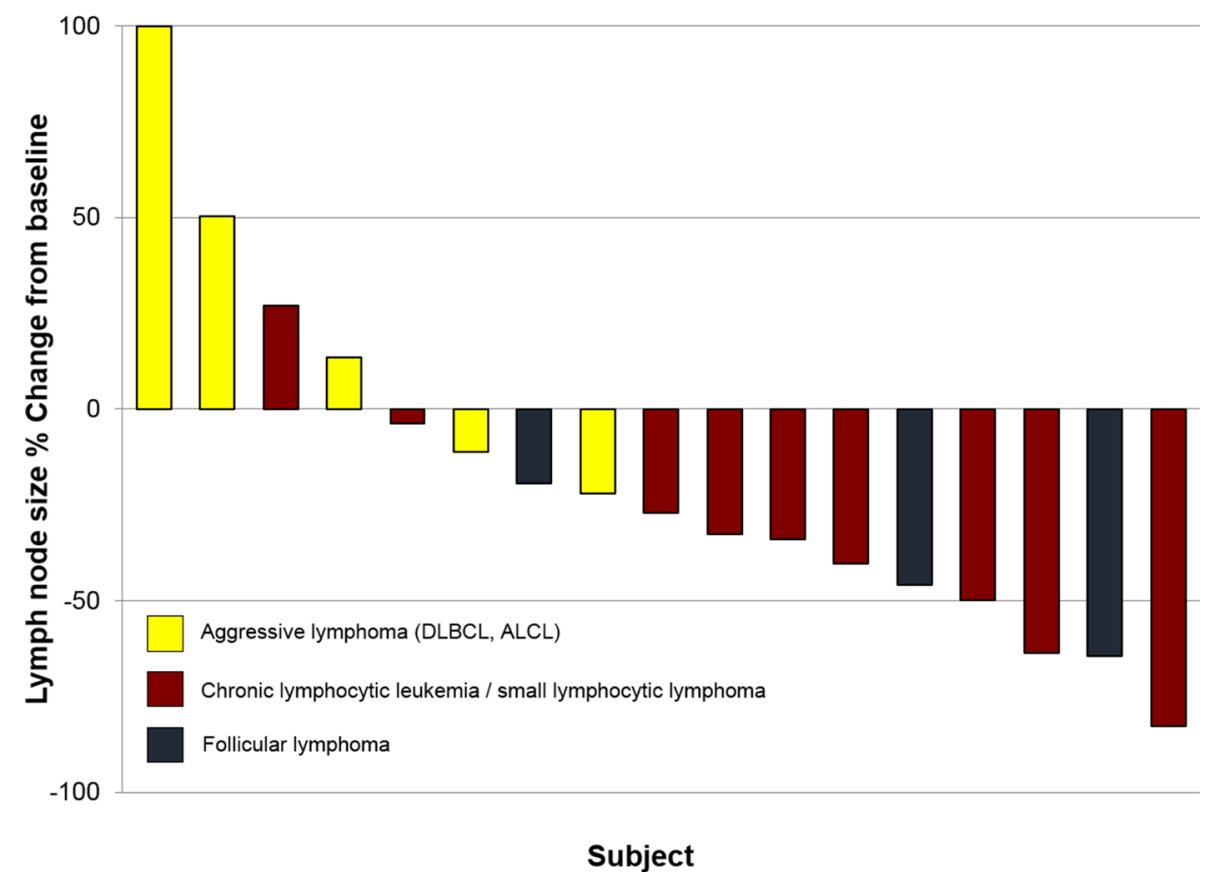

Figure 2: Waterfall plots of best overall response according to response criteria in 17 patients with measurable disease (patients excluded include one subject with CLL and no measurable lymph nodes and two subjects with plasma cell myeloma) (ALCL: anaplastic large cell lymphoma; DLBCL: diffuse large B cell lymphoma; MCL: mantle cell lymphoma).



Figure 3: Kaplan Meier analysis of overall survival from treatment initiation. (OS: Overall Survival). 
these preclinical observations, the rate and severity of neutropenia (grade $\geq 3=60 \%$ ) and thrombocytopenia (grade $\geq 3=25 \%$ ) observed in our study were comparable to those previously reported for fludarabine. In a phase I-II study of single agent fludarabine for relapsed/ refractory CLL [31], the rates of grade $\geq 3$ neutropenia and thrombocytopenia were $56 \%$ and $25 \%$, respectively. Leiby and colleagues reported the results of a phase I study of fludarabine monotherapy for subjects with relapsed nonHodgkin lymphoma [32]; grade 3-4 leukopenia occurred in 4 of 21 subjects and 2 cases of grade 3 thrombocytopenia were observed. Fludarabine was given in continuous infusion, with a smaller total dose per cycle than in our study (initial loading dose of $20 \mathrm{mg} / \mathrm{m}^{2}$ followed by continuous infusion of $30 \mathrm{mg} / \mathrm{m}^{2} /$ day for 48 hours). Several randomized, controlled studies compared fludarabine with alkylating agents or combination chemotherapy [1, 6, 33]. In these trials, hematologic toxicity was common (grade $\geq 3$ neutropenia: 19-38\% ; grade $\geq 3$ thrombocytopenia: 13-15\%; grade $\geq 3$ anemia: 7-18\%). The incidence and severity of anemia observed in our study was higher than that observed with first - line fludarabine monotherapy; this could be secondary to extensive prior therapy in our patient population, but could also be secondary to red blood cell membrane damage by methoxyamine, causing low-grade hemolysis and providing an explanation for decreases in haptoglobin observed in 6 subjects. Grade 3 anemia was observed in previous phase I studies of methoxyamine in combination with pemetrexed [34] or temozolomide [35]. Animal toxicology studies observed extravascular hemolysis at methoxyamine doses 20 times higher than those required for efficacy. Fludarabine has known cumulative hematologic toxicity [36] and it is possible that methoxyamine increases marginally the incidence of this group adverse events. While only 11 of 20 patients received at least three cycles of therapy, we observed that patients who received more than three cycles of the combination therapy had a higher incidence of leukopenia. Treatment duration did not increase the incidence of other hematologic toxicities, again suggesting that the addition of methoxyamine to fludarabine results in limited additional toxicity, with most of the hematologic adverse events manifesting in the first cycles of treatment. In our study, as in previously reported phase I studies of methoxyamine combinations, severe non-hematologic toxicities were rare and not different from reported for single agent fludarabine. Based on these observations and without clear increase in the incidence of toxicity with increasing dose, we concluded $120 \mathrm{mg} / \mathrm{m} 2$ as the recommended phase II dose of methoxyamine when studied in combination with fludarabine.

Previous studies have shown that addition of methoxyamine to fludarabine increased DNA double-strand breaks [24]. In our study, we observed cumulative increases in comet tail length throughout the first week of therapy, indicating progressive DNA damage. The observation of a correlation between decreases in circulating malignant lymphocytes and comet tail length highlights the relevance

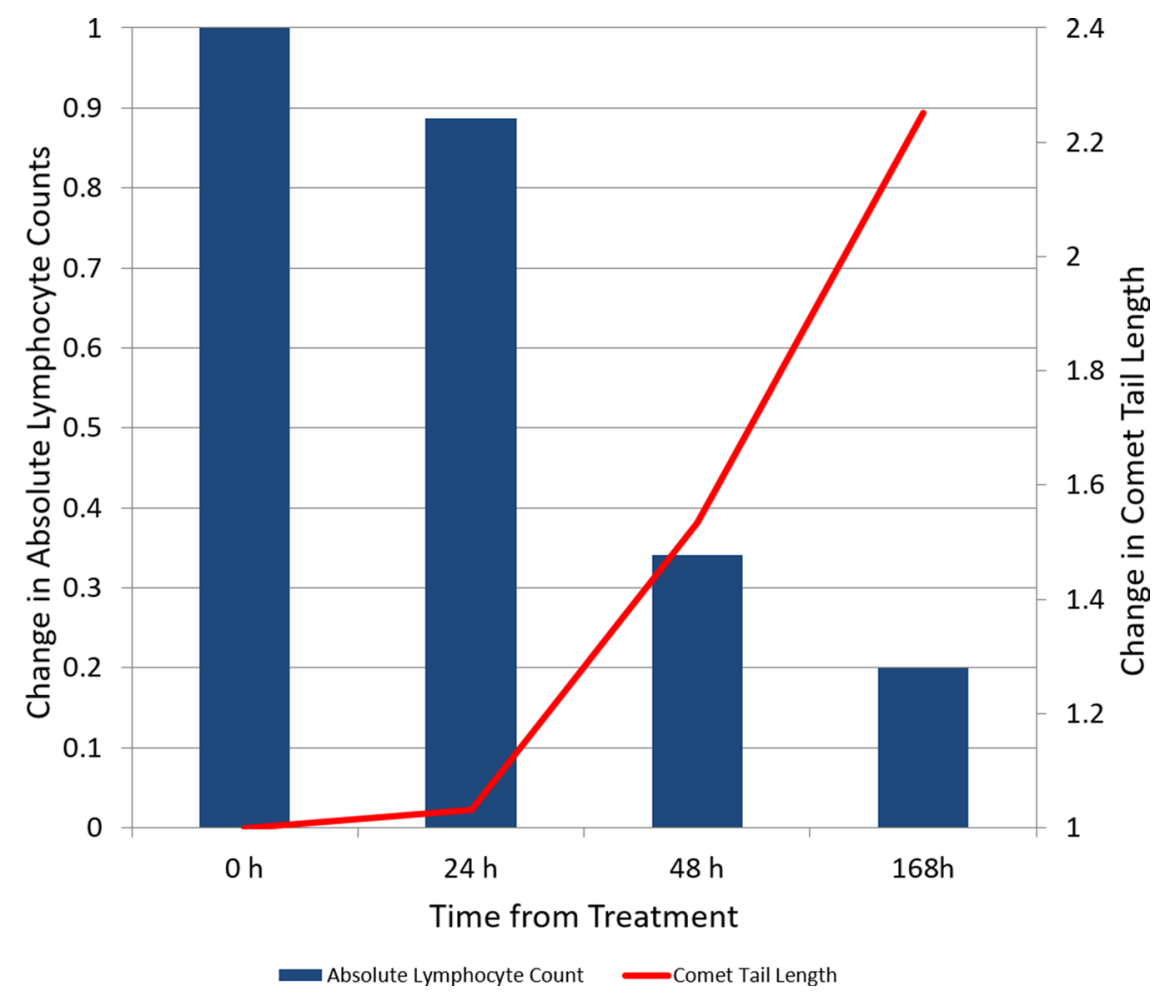

Figure 4: Change over time in absolute lymphocyte count and comet tail length in subjects diagnosed with chronic lymphocytic leukemia with peripheral blood lymphocytosis $(n=7)$. 
of DNA double-strand break measurements as a surrogate marker of the antineoplastic effect of methoxyamine and fludarabine.

As expected, responses were observed in subjects with indolent lymphoid malignancies, including three patients with CLL and one with FL. Among partial responders, two subjects had received prior fludarabine. Patients who achieved at least stable disease included only subjects with lymphoid malignancies. Both plasma cell myeloma subjects presented progressive disease after 2 cycles of therapy, suggesting methoxyamine did not overcome the absence of antimyeloma activity of fludarabine [37]. The concentration of responses and stable disease in cases with indolent lymphoma, and the rapid normalization of lymphocytosis in CLL patients reflects the selective lymphotoxicity of the combination.

Previous studies have demonstrated the safety of methoxyamine when combined with the antimetabolite pemetrexed in solid tumors [38]; phase II studies are evaluating the efficacy of the combination of methoxyamine with pemetrexed, cisplatin and radiation for treatment of non-small cell lung cancer (ClinicalTrials. gov NCT02535325 and NCT02535312). A phase I study investigating the combination of methoxyamine and the alkylator temozolomide for treatment of solid tumors and CNS malignancies has recently been completed [35]. Our present study shows methoxyamine can be safely combined with yet an additional class of antineoplastic agents. Additional in vitro studies are evaluating the combination of methoxyamine with other purine and pyrimidine analogs as well as bendamustine, an alkylating agent with purine analog - like properties used frequently for treatment of indolent lymphoid malignancies [39].

Fludarabine remains a central component of reduced intensity conditioning regimens for hematopoietic progenitor cell transplant. These regimens have more limited antitumor activity, and are primarily designed to be immunosuppressive, primarily through lymphodepletion, relying on the graft to eradicate the underlying neoplasm. Studies are planned to investigate the addition of methoxyamine to fludarabine - containing conditioning regimens, hypothesizing that the combination may result both in increased lymphodepletion as well as improved antineoplastic activity. Additional studies are planned to investigate the use of methoxyamine with alkylating agents used in stem cell transplant conditioning regimens, melphalan and busulfan.

With the introduction of new signaling inhibitors, the role of fludarabine in the treatment of indolent lymphomas and especially CLL has come into question $[40,41]$. However, regimens containing this drug have excellent activity against CLL and remain relevant as preferred first line therapy for certain patient subsets [42]. Our study demonstrates that the addition of methoxyamine is safe and well tolerated and has activity against lymphoid malignancies, including subjects previously treated with fludarabine. The potential of methoxyamine to increase the antineoplastic activity of fludarabine with limited additional toxicity should be evaluated in further studies, both as a means of achieving higher antineoplastic activity and as a dose - sparing strategy.

Enhanced fludarabine activity may broaden its use in lymphoid malignancies as well as in stem cell transplant conditioning regimens, where increase activity of reduced intensity regimens can result in improved disease control.

\section{MATERIALS AND METHODS}

\section{Study population}

Eligible patients were adults older than 18 years of age with hematologic malignancies (excluding acute myeloid leukemia), relapsed after at least one line of therapy (no maximum), Eastern Cooperative Oncology Group performance status $\leq 2$, adequate organ and bone marrow function (creatinine $<1.5 \mathrm{mg} / \mathrm{dl}$ or creatinine clearance $>60 \mathrm{ml} / \mathrm{min} / 1.72 \mathrm{~m}^{2}$; total bilirubin $<1.5 \mathrm{mg} / \mathrm{dl}$, $\mathrm{AST}<2.5$ times upper limit of normal; absolute neutrophil count $>750$; absolute neutrophil count $>750 / \mu$; platelets $>50,000 / \mu \mathrm{l}$ and hemoglobin $>9.0 \mathrm{~g} / \mathrm{dl}$ ). Patients who had progression after fludarabine therapy were eligible. Patients were excluded if they had received treatment within 3 weeks before starting treatment, if they had a history of uncontrolled heart failure (NYHA class III or IV), CNS or leptomeningeal involvement by disease, or if they had known HIV, hepatitis B or C infection.

The study protocol was approved by the institutional review board of University Hospitals Cleveland Medical Center. All patients gave written informed consent. The study was conducted according to good clinical practice and the declaration of Helsinki. It is registered at ClinicalTrials.gov (NCT01658319).

\section{Study design}

This was a single center, open label, dose escalation trial designed to assess the safety and pharmacokinetics of methoxyamine when given in combination with fludarabine. Treatment cycles lasted 28 days. Fludarabine, $25 \mathrm{mg} / \mathrm{m}^{2}$ was given intravenously daily from day 1 through 5; methoxyamine was given intravenously on day 2 of cycle 1 to facilitate pharmacokinetic analysis, and then on day 1 of subsequent cycles. Methoxyamine dose escalation was done in $3+3$ design, in five dose levels between 15 and $120 \mathrm{mg} / \mathrm{m}^{2}$. For further assessment of safety endpoints, the final cohort $\left(120 \mathrm{mg} / \mathrm{m}^{2}\right)$ was expanded to a total of 6 subjects.

\section{Study assessments}

Adverse events were graded for severity according to the National Cancer Institute Common Terminology 
Criteria for Adverse Events (version 4.0). Dose limiting toxicities were defined as those occurring during the first cycle of therapy and included: grade $\geq 3$ non-hematologic toxicities (with the exception of alopecia); grade 4 neutropenia lasting 14 or more days; febrile neutropenia (grade 4 neutropenia with fever $>38.5^{\circ} \mathrm{C}$ ); neutropenic infection (grade $\geq 3$ neutropenia with grade $\geq 3$ infection); grade $\geq 3$ hemolysis and grade $\geq 4$ thrombocytopenia (or grade $\geq$ thrombocytopenia with grade $\geq 3$ hemorrhage).

Baseline tumor measurements included complete blood count, bone marrow aspirate and biopsy and computed tomography (CT) imaging studies. Positron emission tomography imaging was done in patients with lymphomas known to be FDG avid, as delineated by Cheson and colleagues [43]. Serum and urine protein electrophoresis were done in plasma cell myeloma patients. Restaging laboratory and imaging studies were done every 8 weeks and at the end of treatment. The overall response rate was assessed by the investigator based on disease specific criteria [43-45]. Patients were observed for up to 1 year or until disease progression, death, or initiation of new anticancer therapy, whichever occurred first.

\section{Pharmacokinetic studies}

Researchers from the Case Comprehensive Cancer Center developed and validated a liquid chromatography tandem mass spectrometry (LC-MS/MS) method for determining methoxyamine concentration in human plasma samples [46]. Blood samples for pharmacokinetic analysis were collected before methoxyamine infusion and 2, 24, 48, 96 and 168 hours after infusion. The maximum plasma concentration (Cmax), elimination half-life, and area under the curve for methoxyamine concentration were determined. All pharmacokinetic studies were performed by the Translational Research and Pharmacology Core of the Case Comprehensive Cancer Center.

\section{DNA damage measurements by comet assay}

Peripheral blood samples were obtained at baseline, 2 hours after treatment with fludarabine alone on day 1 , immediately before and 2 hours after methoxyamine and fludarabine infusion on day 2 and immediately before infusion of fludarabine on days 3, 4 and 5 .

Peripheral blood mononuclear cells were isolated by Ficoll density gradient centrifugation.

The single cell comet electrophoresis assay was performed using Comet Assay kit (Trevigen, Gaithersburg, MD). Approximately 5000 mononuclear cells (in $50 \mu \mathrm{l}$ ) were mixed with $250 \mu \mathrm{l}$ of $1 \%$ low melting point agarose in $1 \mathrm{X}$ PBS at $37^{\circ} \mathrm{C}$. The mixture $(75 \mu \mathrm{l})$ was pipetted onto a Comet slide (Trevigen, Gaithersburg, MD) and allowed to solidify at $4^{\circ} \mathrm{C}$. Slides were then immersed for 30 minutes in prechilled lysis buffer $(2.5 \mathrm{mM}$ sodium chloride, 100 mM EDTA pH 10, 10 mM Tris Base, 1\% sodium lauryl sarcosinate, $0.01 \%$ Triton $\mathrm{X}-100$ ) at $4^{\circ} \mathrm{C}$. After lysis, slides were incubated for 20 minutes in alkaline solution $(0.3 \mathrm{M} \mathrm{NaOH}, 1 \mathrm{mM}$ EDTA) at room temperature, to allow DNA unwinding, followed by alkaline electrophoresis for the next 30 minutes. The Comet shape in individual mononuclear cells was visualized by staining with the Comet silver staining kit (Trevigen, Gaithersburg, MD). Fifty cells per sample were analyzed using Komet Analysis software (Andor Technology, Belfast, UK). Cellular DNA damage was expressed as the tail "length", tail DNA content, and tail "moment", a measure that combines the length of DNA migration and the relative DNA content therein [47]. All pharmacodynamic assays were performed by the Translational Research and Pharmacology Core of the Case Comprehensive Cancer Center.

\section{Statistical analysis}

To determine whether increasing doses of methoxyamine affect drug clearance we examined the difference among methoxyamine elimination half-lives of each cohort of this study using one-way ANOVA. For the analysis of the Comet assay, two-way ANOVA (with Bonferroni correction for multiple comparisons) was used to compare the means of tail length values at different time points as well as the effect of methoxyamine dose on tail length at different time points. The correlations of tail length values with changes in WBC and absolute lymphocyte count were estimated using linear regression. All tests were two sided and $p$-values were considered statistically significant if lower than 0.05. Statistical analyses were performed using XLSTAT (Addinsoft, New York, NY) and SAS Software (SAS Institute Inc., Cary, NC).

\section{Abbreviations}

AP: Apurinic/apyrimidinic; APE: Apurinic/ apyrimidinic site endonuclease; BER: Base excision repair pathway; CLL: Chronic lymphocytic leukemia; Cmax: Maximum plasma concentration; CT: Computed tomography; DLBCL: Diffuse large B cell lymphoma; F-ara-ATP: Fludarabine triphosphate; FDG: Fludeoxyglucose $\left({ }^{18} \mathrm{~F}\right)$; FL: Follicular lymphoma; LC-MS/ MS: Liquid chromatography tandem mass spectrometry; NER: Nucleotide excision repair pathway; OS: Overall survival; PFS: Progression free survival; SLL: Small lymphocytic lymphoma; WBC: White blood cell.

\section{Author contributions}

Caimi: Designed trial, conducted research, analyzed data, wrote manuscript; Cooper: Conducted research, reviewed manuscript; William: Conducted research, reviewed manuscript; Dowlati: Designed trial, oversaw 
trial conduction, reviewed manuscript; Barr: Designed trial, reviewed manuscript; Fu: Analyzed data, reviewed manuscript; Pink: Conducted pharmacodynamic assays, reviewed manuscript; $\mathrm{Xu}$ : Conducted pharmacokinetic assays, reviewed manuscript; Lazarus: Designed trial, conducted research, reviewed manuscript; de Lima: Conducted research, reviewed manuscript; Gerson: Designed trial, reviewed manuscript.

\section{CONFLICTS OF INTEREST}

SLG holds patents under Case Western Reserve University for the use of methoxyamine, is compensated for service on the Scientific Advisory Board for Tracon, holds shares, and has a royalty and milestone interest through Case Western Reserve University for Methoxyamine (TRC-102). All other authors have no relevant conflicts of interest to disclose.

\section{FUNDING}

Case Comprehensive Cancer Center, Early Phase Clinical Research Support (EPCRS). Principal Investigator: Paolo F. Caimi.

NIH: 5K12CA076917-13; 5K12CA076917-14; 5K12CA076917-15; Physician Scientist Award (Program) (PSA) (K12). Principal Investigator: Stanton L. Gerson.

\section{REFERENCES}

1. Rai KR, Peterson BL, Appelbaum FR, Kolitz J, Elias L, Shepherd L, Hines J, Threatte GA, Larson RA, Cheson BD, Schiffer CA. Fludarabine compared with chlorambucil as primary therapy for chronic lymphocytic leukemia. N Engl J Med. 2000; 343:1750-1757.

2. Hallek M, Fischer K, Fingerle-Rowson G, Fink AM, Busch R, Mayer J, Hensel M, Hopfinger G, Hess G, von Grunhagen U, Bergmann M, Catalano J, Zinzani PL, et al. Addition of rituximab to fludarabine and cyclophosphamide in patients with chronic lymphocytic leukaemia: a randomised, open-label, phase 3 trial. Lancet. 2010; 376: 1164-1174.

3. Zinzani PL, Pellegrini C, Broccoli A, Gandolfi L, Stefoni V, Casadei B, Maglie R, Argnani L, Pileri S. FludarabineMitoxantrone-Rituximab regimen in untreated indolent non-follicular non-Hodgkin's lymphoma: experience on 143 patients. Hematol Oncol. 2015; 33:141-146.

4. Forstpointner R, Dreyling M, Repp R, Hermann S, Hanel A, Metzner B, Pott C, Hartmann F, Rothmann F, Rohrberg R, Bock HP, Wandt H, Unterhalt M, et al. The addition of rituximab to a combination of fludarabine, cyclophosphamide, mitoxantrone (FCM) significantly increases the response rate and prolongs survival as compared with FCM alone in patients with relapsed and refractory follicular and mantle cell lymphomas: results of a prospective randomized study of the German Low-Grade Lymphoma Study Group. Blood. 2004; 104:3064-3071.

5. Guolo F, Minetto P, Clavio M, Miglino M, Di Grazia C, Ballerini F, Pastori G, Guardo D, Colombo N, Kunkl A, Fugazza G, Rebesco B, Sessarego M, et al. High feasibility and antileukemic efficacy of fludarabine, cytarabine, and idarubicin (FLAI) induction followed by risk-oriented consolidation: A critical review of a 10-year, single-center experience in younger, non M3 AML patients. Am J Hematol. 2016; 91:755-762.

6. Johnson S, Smith AG, Loffler H, Osby E, Juliusson G, Emmerich B, Wyld PJ, Hiddemann W. Multicentre prospective randomised trial of fludarabine versus cyclophosphamide, doxorubicin, and prednisone (CAP) for treatment of advanced-stage chronic lymphocytic leukaemia. The French Cooperative Group on CLL. Lancet. 1996; 347:1432-1438.

7. Kekre N, Marquez-Malaver FJ, Cabrero M, Pinana J, Esquirol A, Soiffer RJ, Caballero D, Terol MJ, Martino R, Antin JH, Lopez-Corral L, Solano C, Armand P, et al. Fludarabine/Busulfan versus Fludarabine/Melphalan Conditioning in Patients Undergoing Reduced-Intensity Conditioning Hematopoietic Stem Cell Transplantation for Lymphoma. Biol Blood Marrow Transplant. 2016; 22: 1808-1815.

8. Huang P, Chubb S, Plunkett W. Termination of DNA synthesis by 9-beta-D-arabinofuranosyl-2-fluoroadenine. A mechanism for cytotoxicity. J Biol Chem. 1990; 265: 16617-16625.

9. Gandhi V, Plunkett W. Cellular and clinical pharmacology of fludarabine. Clin Pharmacokinet. 2002; 41: 93-103.

10. Galmarini CM, Mackey JR, Dumontet C. Nucleoside analogues: mechanisms of drug resistance and reversal strategies. Leukemia. 2001; 15:875-890.

11. Sandoval A, Consoli U, Plunkett W. Fludarabine-mediated inhibition of nucleotide excision repair induces apoptosis in quiescent human lymphocytes. Clin Cancer Res. 1996; 2:1731-1741.

12. Yamauchi T, Nowak BJ, Keating MJ, Plunkett W. DNA repair initiated in chronic lymphocytic leukemia lymphocytes by 4-hydroperoxycyclophosphamide is inhibited by fludarabine and clofarabine. Clin Cancer Res. 2001; 7:3580-3589.

13. Rosenwald A, Chuang EY, Davis RE, Wiestner A, Alizadeh AA, Arthur DC, Mitchell JB, Marti GE, Fowler DH, Wilson WH, Staudt LM. Fludarabine treatment of patients with chronic lymphocytic leukemia induces a p53-dependent gene expression response. Blood. 2004; 104: 1428-1434.

14. Rao VA, Plunkett W. Activation of a p53-mediated apoptotic pathway in quiescent lymphocytes after the inhibition of DNA repair by fludarabine. Clin Cancer Res. 2003; 9: 3204-3212.

15. Fromme JC, Verdine GL. Base excision repair. Adv Protein Chem. 2004; 69:1-41. 
16. Srivastava DK, Berg BJ, Prasad R, Molina JT, Beard WA, Tomkinson AE, Wilson SH. Mammalian abasic site base excision repair. Identification of the reaction sequence and rate-determining steps. J Biol Chem. 1998; 273:21203-21209.

17. Fortini P, Parlanti E, Sidorkina OM, Laval J, Dogliotti E. The type of DNA glycosylase determines the base excision repair pathway in mammalian cells. J Biol Chem. 1999; 274:15230-15236.

18. Sokhansanj BA, Rodrigue GR, Fitch JP, Wilson DM 3rd. A quantitative model of human DNA base excision repair. I. Mechanistic insights. Nucleic Acids Res. 2002; 30:1817-1825.

19. Hoeijmakers JH. Genome maintenance mechanisms for preventing cancer. Nature. 2001; 411:366-374.

20. Liu Y, Prasad R, Beard WA, Kedar PS, Hou EW, Shock DD, Wilson SH. Coordination of steps in single-nucleotide base excision repair mediated by apurinic/apyrimidinic endonuclease 1 and DNA polymerase beta. J Biol Chem. 2007; 282:13532-13541.

21. Trivedi RN, Almeida KH, Fornsaglio JL, Schamus S, Sobol RW. The role of base excision repair in the sensitivity and resistance to temozolomide-mediated cell death. Cancer Res. 2005; 65:6394-6400.

22. Goellner EM, Grimme B, Brown AR, Lin YC, Wang XH, Sugrue KF, Mitchell L, Trivedi RN, Tang JB, Sobol RW. Overcoming temozolomide resistance in glioblastoma via dual inhibition of NAD+ biosynthesis and base excision repair. Cancer Res. 2011; 71:2308-2317.

23. Bulgar AD, Weeks LD, Miao Y, Yang S, Xu Y, Guo C, Markowitz S, Oleinick N, Gerson SL, Liu L. Removal of uracil by uracil DNA glycosylase limits pemetrexed cytotoxicity: overriding the limit with methoxyamine to inhibit base excision repair. Cell Death Dis. 2012; 3:e252.

24. Bulgar AD, Snell M, Donze JR, Kirkland EB, Li L, Yang S, $\mathrm{Xu}$ Y, Gerson SL, Liu L. Targeting base excision repair suggests a new therapeutic strategy of fludarabine for the treatment of chronic lymphocytic leukemia. Leukemia. 2010; 24:1795-1799.

25. Liu L, Taverna P, Whitacre CM, Chatterjee S, Gerson SL. Pharmacologic disruption of base excision repair sensitizes mismatch repair-deficient and -proficient colon cancer cells to methylating agents. Clin Cancer Res. 1999; 5: 2908-2917.

26. Liu L, Nakatsuru Y, Gerson SL. Base excision repair as a therapeutic target in colon cancer. Clin Cancer Res. 2002; 8:2985-2991.

27. Taverna P, Hwang HS, Schupp JE, Radivoyevitch T, Session NN, Reddy G, Zarling DA, Kinsella TJ. Inhibition of base excision repair potentiates iododeoxyuridineinduced cytotoxicity and radiosensitization. Cancer Res. 2003; 63:838-846.

28. Rinne M, Caldwell D, Kelley MR. Transient adenoviral $\mathrm{N}$-methylpurine DNA glycosylase overexpression imparts chemotherapeutic sensitivity to human breast cancer cells. Mol Cancer Ther. 2004; 3:955-967.
29. Fishel ML, He Y, Smith ML, Kelley MR. Manipulation of base excision repair to sensitize ovarian cancer cells to alkylating agent temozolomide. Clin Cancer Res. 2007; 13: 260-267.

30. Yan L, Bulgar A, Miao Y, Mahajan V, Donze JR, Gerson SL, Liu L. Combined Treatment with Temozolomide and Methoxyamine: Blocking Apurininc/Pyrimidinic Site Repair Coupled with Targeting Topoisomerase II $\alpha$. Clin Cancer Res. 2007; 13:1532-1539.

31. Keating MJ, Kantarjian H, Talpaz M, Redman J, Koller C, Barlogie B, Velasquez W, Plunkett W, Freireich EJ, McCredie KB. Fludarabine: a new agent with major activity against chronic lymphocytic leukemia. Blood. 1989; 74: $19-25$.

32. Leiby JM, Snider KM, Kraut EH, Metz EN, Malspeis L, Grever MR. Phase II trial of 9-beta-D-arabinofuranosyl2-fluoroadenine 5'-monophosphate in non-Hodgkin's lymphoma: prospective comparison of response with deoxycytidine kinase activity. Cancer Res. 1987; 47: 2719-2722.

33. Leporrier M, Chevret S, Cazin B, Boudjerra N, Feugier P, Desablens B, Rapp MJ, Jaubert J, Autrand C, Divine M, Dreyfus B, Maloum K, Travade P, et al. Randomized comparison of fludarabine, CAP, and ChOP in 938 previously untreated stage $\mathrm{B}$ and $\mathrm{C}$ chronic lymphocytic leukemia patients. Blood. 2001; 98:2319-2325.

34. Weiss GJ, Gordon MS, Rosen S, Savvides P, Adams BJ, Alvarez L, Liu L, Xu Y, Gerson SL, Leigh BR. Final results from a phase I study of oral TRC102 (methoxyamine $\mathrm{HCl}$ ), an inhibitor of base-excision repair, to potentiate the activity of pemetrexed in patients with refractory cancer. J Clin Oncol. 2010; 28:2576.

35. Eads JR, Krishnamurthi SS, Saltzman JN, Meropol NJ, Bokar JA, Koon HB, Sharma N, Savvides P, Pink J, Xu Y, Beumer JH, Fu P, Beatty K, et al. Phase I clinical trial temozolomide and methoxyamine (TRC-102) in patients. J Clin Oncol. 2015; 33:2558.

36. Bouvet E, Borel C, Oberic L, Compaci G, Cazin B, Michallet AS, Laurent G, Ysebaert L. Impact of dose intensity on outcome of fludarabine, cyclophosphamide, and rituximab regimen given in the first-line therapy for chronic lymphocytic leukemia. Haematologica. 2013; 98:65-70.

37. Kraut EH, Crowley JJ, Grever MR, Keppen MD, Bonnet JD, Hynes HE, Salmon SE. Phase II study of fludarabine phosphate in multiple myeloma. A Southwest Oncology Group study. Invest New Drugs. 1990; 8:199-200.

38. Gordon MS, Rosen LS, Mendelson D, Ramanathan RK, Goldman J, Liu L, Xu Y, Gerson SL, Anthony SP, Figg WD, Spencer S, Adams BJ, Theuer CP, et al. A phase 1 study of TRC102, an inhibitor of base excision repair, and pemetrexed in patients with advanced solid tumors. Invest New Drugs. 2013; 31:714-723.

39. Hiraoka N, Kikuchi J, Yamauchi T, Koyama D, Wada T, Uesawa M, Akutsu M, Mori S, Nakamura Y, Ueda T, 
Kano Y, Furukawa Y. Purine analog-like properties of bendamustine underlie rapid activation of DNA damage response and synergistic effects with pyrimidine analogues in lymphoid malignancies. PLoS One. 2014; 9:e90675.

40. Byrd JC, Jones JJ, Woyach JA, Johnson AJ, Flynn JM. Entering the era of targeted therapy for chronic lymphocytic leukemia: impact on the practicing clinician. J Clin Oncol. 2014; 32:3039-3047.

41. Jain N, O'Brien S. Targeted therapies for CLL: Practical issues with the changing treatment paradigm. Blood Rev. 2016; 30:233-244.

42. Eichhorst B, Fink AM, Bahlo J, Busch R, Kovacs G, Maurer C, Lange E, Koppler H, Kiehl M, Sokler M, Schlag R, Vehling-Kaiser U, Kochling G, et al. First-line chemoimmunotherapy with bendamustine and rituximab versus fludarabine, cyclophosphamide, and rituximab in patients with advanced chronic lymphocytic leukaemia (CLL10): an international, open-label, randomised, phase 3, non-inferiority trial. Lancet Oncol. 2016; 17:928-942.

43. Cheson BD, Pfistner B, Juweid ME, Gascoyne RD, Specht L, Horning SJ, Coiffier B, Fisher RI, Hagenbeek A, Zucca E, Rosen ST, Stroobants S, Lister TA, et al. Revised response criteria for malignant lymphoma. J Clin Oncol. 2007; 25:579-586.
44. Durie BG, Harousseau JL, Miguel JS, Blade J, Barlogie B, Anderson K, Gertz M, Dimopoulos M, Westin J, Sonneveld P, Ludwig H, Gahrton G, Beksac M, et al. International uniform response criteria for multiple myeloma. Leukemia. 2006; 20:1467-1473.

45. Hallek M, Cheson BD, Catovsky D, Caligaris-Cappio F, Dighiero G, Dohner H, Hillmen P, Keating MJ, Montserrat E, Rai KR, Kipps TJ, International Workshop on Chronic Lymphocytic Leukemia. Guidelines for the diagnosis and treatment of chronic lymphocytic leukemia: a report from the International Workshop on Chronic Lymphocytic Leukemia updating the National Cancer Institute-Working Group 1996 guidelines. Blood. 2008; 111:5446-5456.

46. Yang S, Savvides P, Liu L, Gerson SL, Xu Y. Development and validation of an LC-MS/MS method for pharmacokinetic study of methoxyamine in phase I clinical trial. J Chromatogr B Analyt Technol Biomed Life Sci. 2012; 901:25-33.

47. Lovell DP, Omori T. Statistical issues in the use of the comet assay. Mutagenesis. 2008; 23:171-182. 